\section{Principios e prática em transtornos do espectro obsessivo-compulsivo}

Irismar Reis de Oliveira, Maria Conceição Rosário, Eurípides Constantino Miguel. Guanabara Koogan, 2007. ISBN 978-85277-1386-3

Freqüentemente se utiliza o conceito de espectro em psiquiatria para definir entidades nosológicas distintas, mas com apresentações sintomatológicas semelhantes, que ocorrem dentro de um determinado continuum. Os transtornos do espectro obsessivo-compulsivo (TEOC) apresentam diversas relações entre si, como características psicopatológicas, evolução clínica, comorbidades e respostas terapêuticas similares. Fazem parte desse espectro, dentre outros, o transtorno obsessivo-compulsivo (TOC), os transtornos de tiques, como a síndrome de Tourette (ST), o transtorno dismórfico corporal, a tricotilomania, o jogo compulsivo, o transtorno do comprar compulsivo e demais transtornos de controle de impulsos.

Dentro deste espectro, o TOC e os transtornos de tiques, especialmente a ST, são os que apresentam uma associação mais bem estabelecida, não somente por possuírem características clínicas similares, mas também por evidências de estudos epidemiológicos, genéticos, de neuroimagem e de resposta ao tratamento que sugerem a hipótese de um subgrupo de pacientes com TOC associado a tiques. O presente livro destina-se a oferecer uma compreensão na atualização clínica, etiológica e terapêutica dos TEOC, mais especificamente do TOC e dos transtornos de tiques.

O livro está dividido em 14 capítulos os quais englobam os mais variados aspectos dos TEOC. O capítulo 1 realiza uma revisão histórica e aborda as origens dos sintomas obsessivos compulsivos. Os capítulos 2 e 3 compreendem as características psicopatológicas do TOC e seu aspecto heterogêneo, além de apresentar uma abordagem dimensional do TOC, a qual tem sido utilizada na tentativa de determinar subgrupos mais homogêneos de pacientes com TOC. Os capítulos 4 e 5 trazem informações sobre etiologia, diagnóstico e tratamento da ST e dos TEOC, respectivamente. O capítulo 6 descreve os principais aspectos genéticos dos TEOC e ressalta a maior associação genética entre o TOC e os transtornos de tiques. Os aspectos etiológicos envolvendo fatores neuropsicológicos e estudos de neuroimagem são apresentados nos capítulos 7 e 8 . 0 capítulo 9 descreve os aspectos imunológicos no TOC e suas implicações no tratamento. Os capítulos subseqüentes tratam das abordagens terapêuticas, tanto farmacológicas quando psicoterápicas, no tratamento dos TEOC. O capítulo 10 apresenta as principais características do tratamento psicofarmacológico do TOC e de alguns quadros associados aos TEOC, mais especificamente a ST, o transtorno dismórfico corporal e a tricotilomania. O capítulo 11 e o capítulo 12 descrevem o modelo cognitivo-comportamental e a terapia cognitivo-comportamental do TOC. São apresentadas as principais técnicas comportamentais e cognitivas, as etapas dessa abordagem psicoterápica e as evidências que comprovam a eficácia da terapia cognitivo-comportamental no tratamento do TOC. O capítulo 13 descreve rapidamente a apresentação clínica do TOC na infância e adolescência e apresenta os princípios gerais da terapia cognitivocomportamental em crianças e adolescentes. O livro termina com o capítulo 14, o qual ressalta a importância da participação de

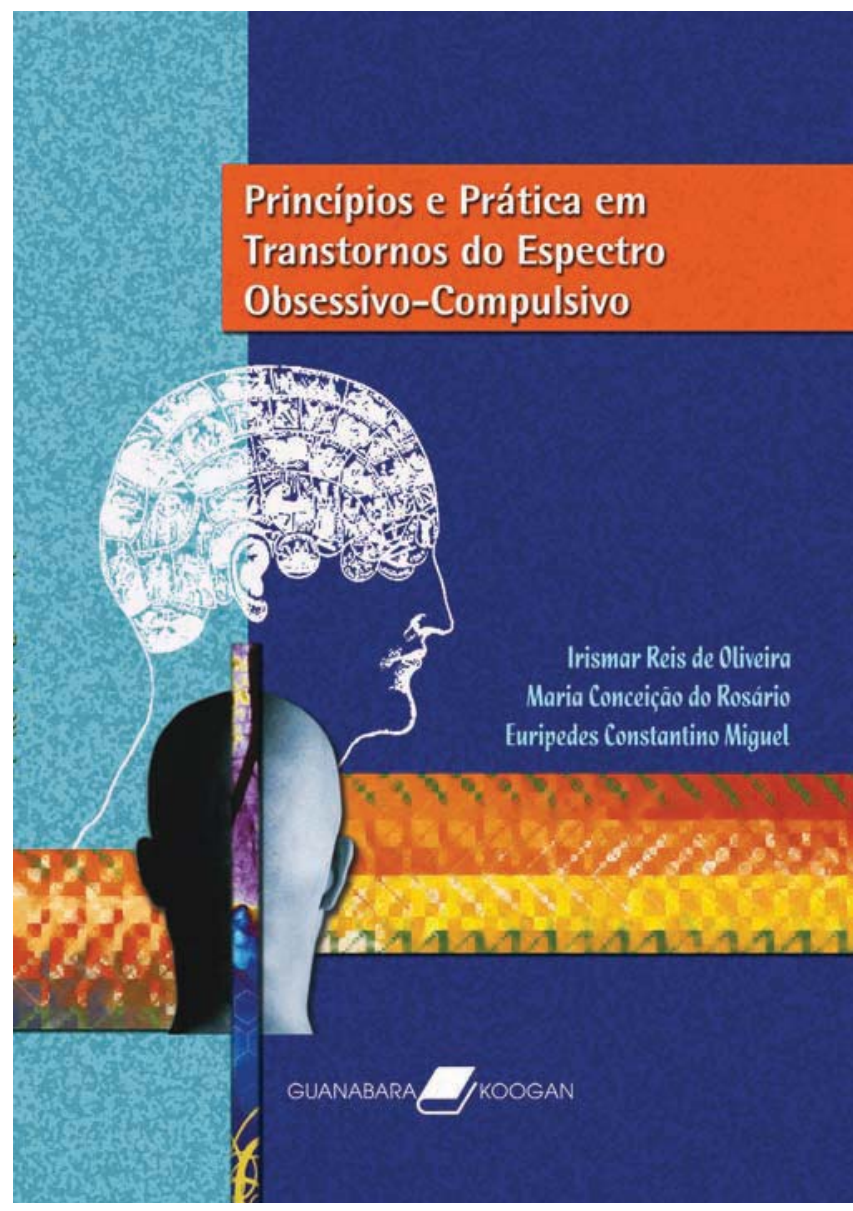

familiares e portadores em associações e grupos de apoio como a Associação Brasileira de Portadores de Síndrome de Tourette, Tiques e Transtorno Obsessivo-Compulsivo (ASTOC) e a Associação Bahiana de Síndrome de Tourette, Tiques e Transtorno ObsessivoCompulsivo (ABASTOC).

O presente livro, organizado por profissionais de diferentes regiões do país, altamente conceituados e experientes tanto clinicamente quando academicamente, consegue oferecer uma abordagem atual, objetiva e aprofundada dos TEOC. Penso que uma lacuna, o que não diminui a importância do presente livro, é a escassez de capítulos específicos envolvendo crianças e adolescentes. Apesar de um ter um capítulo dedicado à psicoterapia cognitivocomportamental do TOC e da ST na infância e adolescência, penso que há uma carência de dados referentes à apresentação clínica e aos aspectos do tratamento psicofarmacológico nessa faixa etária.

Por fim, esse livro cumpre plenamente seu objetivo. Trata-se de um livro imprescindível sobre os TEOC, especialmente TOC e transtornos de tique, recomendado aos profissionais de saúde, em particular aos psiquiatras e psicólogos, aos estudantes dessas áreas e, devido a sua linguagem clara e acessível, aos pacientes e a seus familiares.

Luciano Isolan

Universidade Federal do Rio Grande do Sul (UFRGS), Porto Alegre (RS), Brasil 